\title{
Perancangan Geographic Information System Berbasis Android Untuk Potensi Mebel Di Kecamatan Tahunan Kabupaten Jepara
}

\author{
Teguh Tamrin ${ }^{1}$, Akhmad Khanif Zyen ${ }^{2}$, Maula Hashina Dina ${ }^{3}$ \\ 123 Universitas Islam Nahdlatul Ulama Jepara
}

\begin{abstract}
Jepara is a city called carving city because it has a large furniture and carving industry potential. Tahunan Subdistrict is an area located in Jepara regency with the biggest potential of the furniture industry compared to other districts. Everyone who wants to buy furniture from Tahunan may visit the showroom which is located not far from the main road because of the limited information about the potential of furniture, especially small and medium business category in less strategic locations. Judging from these problems, it is necessary to make an information system about the potential of furniture in Tahunan district based on android that is easy to use and integrated with Geographic Information System (GIS) to make it easier for users to find directions to the location. The system development method used is Rapid Application Development (RAD) with Construct 2 as the maker of the application.
\end{abstract}

Keywords: GIS, Android, Furniture, Jepara

\begin{abstract}
Abstrak
Jepara adalah kota yang disebut kota ukiran karena memiliki industri mebel dan ukiran yang besar potensi. Kecamatan Tahunan adalah daerah yang terletak di Kabupaten Jepara dengan potensi industri mebel terbesar dibandingkan dengan kabupaten lain. Setiap orang yang ingin membeli furnitur dari Tahunan dapat mengunjungi showroom yang terletak tidak jauh dari jalan utama karena terbatasnya informasi tentang potensi furnitur, terutama kategori usaha kecil dan menengah di lokasi yang kurang strategis. Dilihat dari masalahmasalah tersebut, maka perlu dibuat suatu sistem informasi tentang potensi furnitur di Kabupaten Tahunan berbasis android yang mudah digunakan dan terintegrasi dengan Sistem Informasi Geografis (SIG) untuk memudahkan pengguna menemukan arah ke lokasi. . Metode pengembangan sistem yang digunakan adalah Rapid Application Development (RAD) dengan Construct 2 sebagai pembuat aplikasi.
\end{abstract}

Kata Kunci : GIS, Android, Furniture, Jepara

ISSN 2715-0143 (online) ISSN 2714-9048 (print)

http://journal.walisongo.ac.id/index.php/jit/index

WJIT : Walisongo Journal of Information Technology - Vol.1 No. 2 (2019) 


\section{PENDAHULUAN}

Jepara merupakan salah satu kabupaten yang terdapat di provinsi Jawa Tengah dengan banyak potensi industri. Mulai dari industri berskala kecil sampai besar banyak ditemui di kabupaten Jepara. Industri Kecil Menengah (IKM) sendiri merupakan salah satu industri yang sangat penting untuk membantu menanggulangi kemiskinan karena bisa menyerap tenaga kerja sebanyak $99,45 \%$ [1].

Salah satu kecamatan yang memiliki potensi besar terhadap IKM mebel dan ukiran ialah kecamatan Tahunan yang letaknya strategis dan memiliki akses menjual lagi barang mebelnya akan memilih langsung mendatangi pengrajin terutama di industri skala kecil menengah, karena selain harganya relatif lebih murah juga bisa memesan sesuai desain yang mereka inginkan. Namun pembeli mengalami kesulitan untuk mendapatkan informasi tentang lokasi pengrajin mebel karena kebanyakan pengrajin tidak memiliki media promosi yang terakses dengan internet seperti website atau layanan google maps. Perkembangan teknologi zaman sekarang yang semakin canggih di berbagai bidang membuat pemanfaatan teknologi informasi peneliti memanfaatkan teknologi mobile semakin berkembang pula. Dalam Hal ini internet mejadi sarana informasi dan komunikasi yang sangat penting bagi pengembangan segala bidang termasuk bidang industri. Salah satu pemanfaatan internet sebagai sarana informasi yang sedang berkembang pesat adalah penemuan teknologi Geographic Information System (GIS) yaitu suatu sistem informasi berbasis komputer guna menyimpan, mengelola, dan menganalisis serta memanggil data berdasarkan letak geografis suatu wilayah [3]. Dengan menggunakan GIS pengguna dengan mudah mendapatkan informasi mengenai lokasi industri atau pengrajin yang berada jauh dari jalan utama dengan lebih efektif dan menghemat waktu karena pembeli tinggal mengikuti petunjuk lokasi yang ada pada aplikasi berbasis GIS. Dengan berbagai permasalhan tersebut, maka dibutuhkan suatu sistem yang menunjukkan pemetaan potensi industry mebel skala kecil menengah di kecamatan Tahunan dengan memanfaatkan teknologi yang semakin berkembang yaitu android dan GIS sehingga memudahkan pencarian informasi mebel secara online dan dapat mengetahui lokasi persebaran industri mebel. Aplikasi ini juga memberi informasi tentang nama usaha mebel, jenis produk, contoh barang, tips tentang mebel dan kontak yang bisa dihubungi oleh pembeli sehingga menjadi informasi yang bermanfaat bagi calon pembeli. Berdasarkan permasalahan dan analisis tersebut, penulis akan membuat sistem dengan menggunakan Construct 2 sebagai tool pembuat aplikasinya. Sedangkan untuk mendapatkan data pengrajin mebel maka penulis menggunakan metode observasi dan GIS yang datanya didapatkan dari Google Maps API. Metode 
Perancangan Geographic Information System Berbasis Android Untuk Potensi Mebel Di Kecamatan Tahunan Kabupaten Jepara

pengembangan menggunakan ode Rapid Application Development (RAD) yang sudah tersusun secara sistematis meliputi requirements planning, design system dan implementation. Aplikasi ini penulis beri nama Potensi Mebel Tahunan Jepara (POMETA JEPARA).

\section{METODE PENELITIAN}

\subsection{Desain Penelitian}

Penelitian yang digunakan melalui pendekatan deskriptif kualitatif yang lebih terfokus pada data sesuai fakta atau kejadian di lokasi penelitian. Proses pengumpulan data diambil dari observasi, wawancara dan dokumentasi di lokasi penelitian yakni wilayah kecamatan Tahunan dengan mengambil sampel sebanyak 16 lokasi usaha mebel berskala kecil sampai menengah.

Pada tahapan ini akan dilakukan perencanaan awal penelitian sesuai dengan metode yang digunakan yakni Rapid Application Development (RAD). Dimulai dari melakukan analisis kebutuhan data, analisis kebutuhan alat dan bahan serta analisis fungsionalitas sistem agar mengetahui fitur informasi apa yang nanti akan ditampilkan pada aplikasi ini. Selanjutnya melakukan desain sistem yang akan diterapkan dengan menggunakan use case diagram, activity diagram dan sequence diagram untuk menjelaskan alur program. Tahapan akhir dari metode ini adalah implementasi yakni memproses data yang sudah diperoleh menjadi data yang terkomputerisasi melalui tahapan pembuatan aplikasi berbasis android menggunakan tools Construct
2 sehingga aplikasi dapat diimplementasikan ke dalam device berbasis android.

Tahap terakhir dari penelitian adalah pengujian produk yang dilakukan ahli media yaitu menggunakan metode black box testing dan uji kelayakan produk oleh ahli materi dan responden masyarakat umum sehingga mengetahui apakah aplikasi ini layak digunakan atau tidak.

\subsection{Pengumpulan Data}

Metode pengumpulan data yang dipakai dalam "Perancangan Geographic Information System Berbasis Android untuk Pemetaan Potensi Mebel di Kecamatan Tahunan Kabupaten Jepara" ini dilakukan dengan :

\subsubsection{Observasi}

Pengamatan terhadap suatu objek yang diteliti baik secara langsung maupun tidak langsung ke lokasi untuk mendapatkan data yang dibutuhkan dalam penelitian [16]. Metode observasi dilakukan dengan pengamatan langsung di 16 lokasi usaha mebel yang berada di wilayah kecamatan Tahunan kabupaten Jepara. Pengamatan yang dilakukan seperti : Mengamati lokasi yang nantinya akan dimasukkan dalam GIS dan mengamati produk apa saja yang dihasilkan masingmasing pemilik usaha. Selain itu juga mengamati kendala- kendala yang sering dialami oleh pemilik usaha.

\subsubsection{Wawancara}

Metode wawancara dilakukan dengan bertanya langsung kepada pengusaha yang terkait yang 
berlokasi di kecamatan tahunan kabupaten jepara. Adapun hal yang ditanyakan antara lain : nama usaha mebel, apa saja produk yang dihasilkan, alamat lengkap dan kontak pemilik usaha.

\subsubsection{Studi Pustaka}

Pada tahap pengumpulan data yaitu mempelajari teori-teori dari buku, jurnal, internet dan teori-teori yang berhubungan dengan masalah yang dibutuhkan [16]. Pada penelitian ini penulis mendapatkan data potensi industri Jepara dari internet dan Disperindag kabupaten Jepara.

\subsubsection{Dokumentasi}

Dokumen merupakan catatan penelitian yang sudah berlalu berupa tulisan, gambar

maupun karya monumental dari pencipta sebelumnya[17]. Dokumentasi dalam penelitian ini adalah foto yang diambil saat melakukan observasi berupa foto kegiatan dan contoh barang yang diproduksi.

\subsubsection{Pengolahan Data Awal}

Data diperoleh melalui studi pustaka akan digunakan sebagai acuan untuk melakukan observasi lapangan secara langsung. Kemudian dilakukan analisa kebutuhan untuk mengetahui fitur-fitur yang dibutuhkan dalam aplikasi, selanjutnya data yang sudah didapatkan diolah untuk dibuat desain sistem yang kemudian dirancang menjadi sebuah aplikasi mengunakan tools Construct 2 .
Tujuan dari pengolahan data awal ini untuk memastikan kesesuaian antara sistem aplikasi dengan kebutuhan pengguna.

\subsubsection{Metode Pengembangan Sistem}

Penelitian ini meggunakan

metode pengembangan Rapid Application Development (RAD). RAD merupakan proses perkembangan suatu perangkat lunak sekuensial linier untuk menekankan perkembangan waktu yang singkat [18].Dengan menggunakan metode RAD bisa mengurangi kebutuhan yang terkaitan degan biaya projek dan sumber daya manusia sehingga dapat menghemat waktu keseluruhan fase . berubahnya desain sistem dalam metode RAD bisa berpengaruh dengan sangat cepat dibanding dengan pendekatan tradisional. Hal ini memudahkan penulis ketika ada perubahan alur atau fitur dari user, sehingga penulis memilih menggunakan metode RAD untuk penelitian ini. Menurut Kendall (2010) Pada pengembangan metode RAD memiliki beberapa tahapan yaitu :

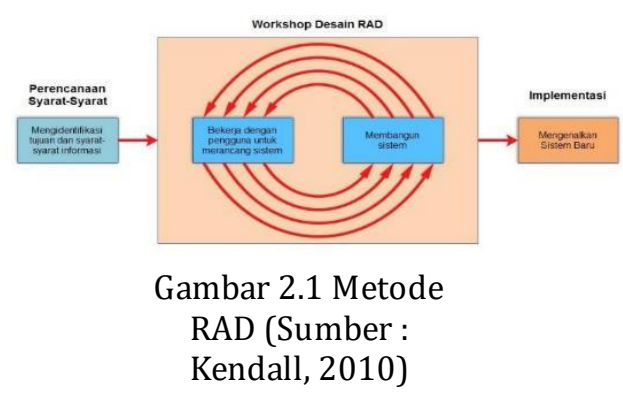

\subsubsection{Tahap Kebutuhan (Requirement Planning)}

Ini adalah tahap awal dan penting dalam 
Perancangan Geographic Information System Berbasis Android Untuk Potensi Mebel Di Kecamatan Tahunan Kabupaten Jepara

penggunaan metode RAD. Pada tahap ini Peneliti memulai dengan mengumpulkan beberapa informasi dari data yang diberikan, observasi secara langsung ke lokasi penelitian yakni tempat usaha dan mengunjungi serta melakukan wawancara pada 16 pemilik usaha mebel. Tujuan dalam pembuatan aplikasi ini, diharapkan dapat memecahkan masalah yang dialami oleh pembeli barang mebel yaitu kurangnya informasi tentang potensi mebel di kecamatan Tahunan kabupaten Jepara.

\subsubsection{Tahap Desain}

Pada tahapdesain peneliti membuat desain awal aplikasi yang sesuai dengan Pengguna, menentukan desain interface dan pembuatan UML yang mengalami perkembangan yang sangat pesat, mobile GIS dapat menangkap,menyimpan,mengupdate, manipulasi, analisa serta dapat menampilkan suatu informasi geografi lewat perangkat seluler. [7]

\subsubsection{Implementasi}

Setelah tahap desain sudah dibuat dengan baik dan sesuai, selanjutnya tahap implementasi desain yakni membuat aplikasi menggunakan construct 2 dan melakukan proses building sehingga aplikasi bias diimplementasikan pada perangkat android. Selanjutnya dilakukan tahap implementasi perangkat pada pengguna sehingga dapat mengetahui apakah aplikasi berjalan sesuai desain sistem yang dibuat atau masih perlu perbaikan. Pada tahap ini juga akan dijelaskan mengenai sistem yang dirancang serta cara penggunaan aplikasi ini kepada para pengguna.

\section{KERANGKA TEORI}

\subsection{Mobile GIS}

Mobile GIS (Geographic

Information System) adalah cara kerja software maupun hardware untuk mengakses data serta layanan geospasial melalui mobile via jaringan kabel maupun nirkabel. GIS merupakan gabungan dari tiga teknologi, yaitu software GIS, teknologi GPS (Global Positioning System), dan perangkat telepon selular (smartphone) yang membuat database dapat diakses oleh seseorang secara langsung atau realtime sehingga memudahkan pengguna mengetahui informasi lewat telepon seluler atau smartphone. Teknologi GIS mengalami perkembangan sangat pesat, dimana mobile GIS bisa menangkap, menyimpan, mengupdate , memanipulasi, menganalisa serta menampilkan informasi geografi dengan mudah lewat perangkat seluler. [7]

\subsection{Industri Mebel}

Industri mebel adalah pekerja sector pengrajin informal menggunakan bermacam-macam jenis kayu , proses produksi menggunakan cara kerja yang sifatnya tradisional. Mebel kayu adalah bahasa untuk peralatan rumah tangga berupa:depan(tempat tidur),kursi,bangku,meja dan lainya yang berfungsi menaruh barang di atasnya. [9]

\subsection{Industri Kecil dan Menengah (IKM)}

Industri Kecil dan Menengah 
(IKM) adalah usaha rumah tangga yang mempunyai kegiatan usaha yang sama yaitu kegiatan produksi. Industri kecil serta menengah dapat dibedakan dari banyaknya tenaga kerja yang digunakan untuk melakukan suatu produksi. [10]

Kriteria UMKM menurut UU nomor 20 Tahun 2008 dapat digolongkan berdasarkan besaran jumlah asset dan besaran omset oleh sebuah usaha sebagai berikut :

Tabel 2.1 Kriteria UMKM

\begin{tabular}{|c|l|l|l|}
\hline No & Usaha & Kriteria & Kriteria \\
\hline 1 & $\begin{array}{l}\text { Usaha } \\
\text { Mikro }\end{array}$ & Maks. & Maks. \\
50 Juta & 300 Juta \\
\hline 2 & $\begin{array}{l}\text { Usaha } \\
\text { Kecil }\end{array}$ & $\begin{array}{l}>50 \\
\text { Juta- } \\
500 \text { Juta }\end{array}$ & $\begin{array}{l}\text { J300 } \\
\text { Juta-2,5 } \\
\text { Miliar }\end{array}$ \\
\hline 3 & $\begin{array}{l}\text { Usaha } \\
\text { Menengah }\end{array}$ & $\begin{array}{l}500 \text { Juta- } \\
10 \text { Miliar }\end{array}$ & $\begin{array}{l}>2,5 \\
\text { Miliar-50 } \\
\text { Miliar }\end{array}$ \\
\hline
\end{tabular}

4. Hasil DAN PEMBAHASAN

\subsection{Perancangan Aplikasi}

Rancangan aplikasi mobile yang berbasis android ini memakai metode Rapid Application Development (RAD) dengan urutan atau tahapan Requirement Planning, Workshop Design, dan Implementation.

\subsection{Perancangan Antarmuka}

Perancangan antarmuka dilakukan sebelum melakukan implementasi agar mencapai hasil yang maksimal. Rancangan aplikasi yang akan dibuat terdiri dari rancangan splash screen, menu utama, menu tentang mebel, menu tentang aplikasi, menu kategori, daftar toko, informasi detail, dan tampian peta memakai Google Maps API.

1) Perancangan Halaman Splash Screen

Rancangan splash screen merupakan perancangan halaman yang akan muncul pertama kali ketika aplikasi dijalankan,

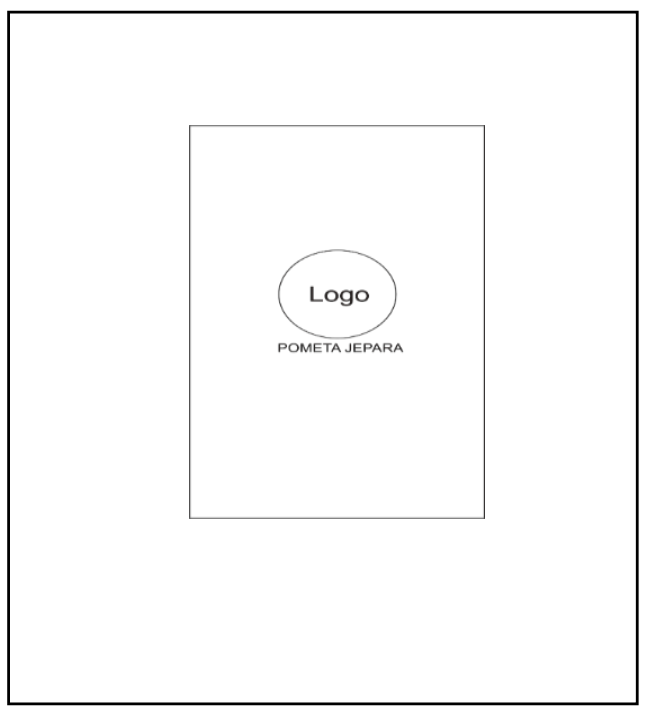

Gambar 4.1 Tampilan Splash Screen

\section{2) Perancangan Halaman Utama}

Perancangan halaman utama merupakan perancangan halaman yang muncul setelah splash screen. Pada halaman ini terdapat dua menu yaitu menu info dan menu daftar mebel.

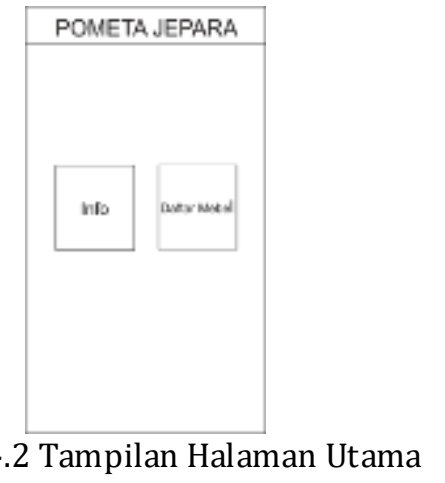


Perancangan Geographic Information System Berbasis Android Untuk Potensi Mebel Di Kecamatan Tahunan Kabupaten Jepara

\section{3) Perancangan Halaman Info}

Perancangan halaman info merupakan perancangan halaman yangberisi duamenuyaitu info tentang aplikasi dan info tentang mebel Jepara.

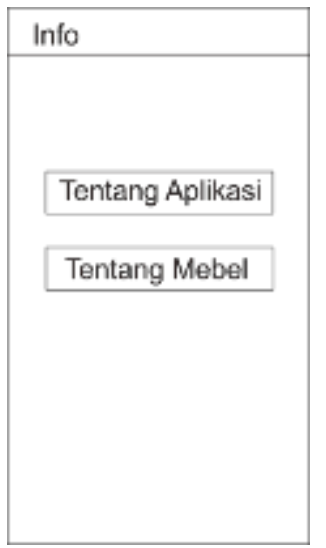

Gambar 4.3 Tampilan Halaman Info

\section{4) Perancangan Menu Daftar Mebel}

Perancangan halaman Menu Daftar Nama Usaha merupakan halaman yang berisi daftar Nama usaha dan lokasinya berada di desa.

\begin{tabular}{|l|}
\hline \multicolumn{1}{|c|}{ Daflar Mebel } \\
\hline Nama Usaha \\
\hline Nama Usaha \\
\hline \\
\hline Narna Usaha \\
\hline Nama Usaha \\
\hline Nama Usaha \\
\hline
\end{tabular}

Gambar 4.4 Tampilan Halaman Daftar Mebel

\subsection{Build Project}

Tahapan ini adalah tahap akhir pada pembuatan aplikasi Pometa Jepara. Yaitu tahap untuk mengubah project Consctruct 2 menjadi aplikasi berbasis android menggunakan Android Studio dan Cordova CLI. Berikut tahapan prosesnya :

1) Mengexport file Construct 2 menjadi project Cordova

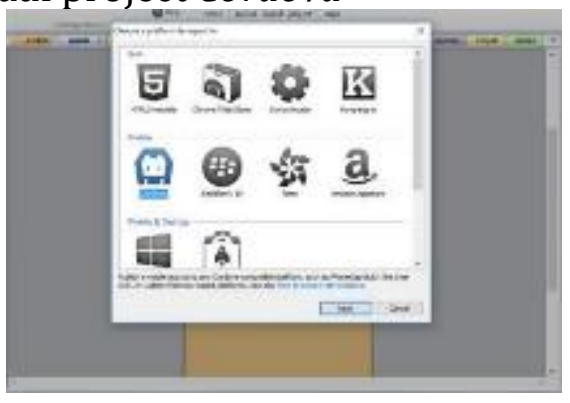

Gambar 4.5 Export File Construct menjadi Cordova

2) Membuat Project Cordova pada cmd

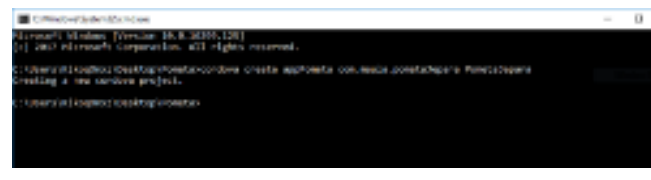

Gambar 4.6 Membuat Project Cordova

3) Masuk ke App Project yang sudah dibuat

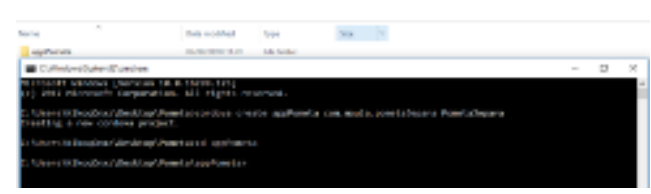

Gambar 4.7 Masuk ke project yang sudah dibuat

4) Menambahkan platform Android pada project cordova dan android studio. 


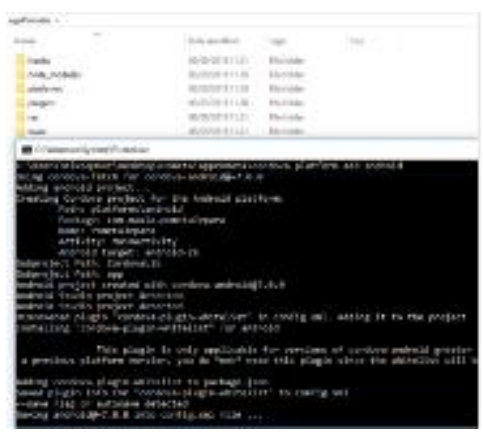

Gambar 4.8 Menambahkan platform android

\subsection{Implementasi Aplikasi}

Setelah proses building aplikasi sukses, maka aplikasi siap diimplementasikan pada device android. Berikut tampilan aplikasi yang telah dijalankan :

1) Tampilan Icon Aplikasi

Tampilan Icon aplikasi Pometa Jepara setelah terinstal di device android.

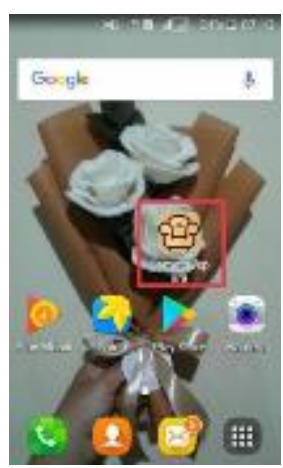

Gambar 4.9 Tampilan icon aplikasi

2) Tampilan Halaman Splash

Screen

Halaman ini adalah halaman yang pertama kali muncul selama beberapa detik saat membuka aplikasi.

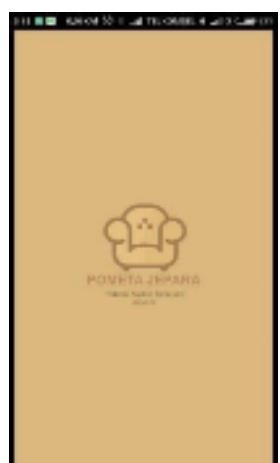

Gambar 4.10 Halaman Splash Screen

3) Tampilan Halaman Utama Halaman ini adalah halaman utama yang berisi dua menu utama yaitu Info dan Daftar Mebel.

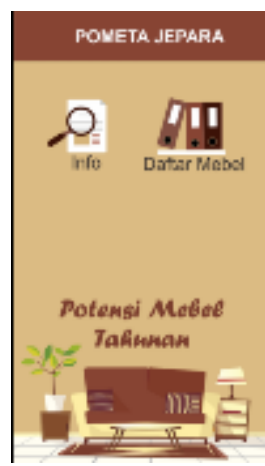

Gambar 4.11 Halaman Utama

4) Tampilan Halaman InfoHalaman ini adalah halaman yang berisidua menu info yaitu menu info TentangAplikasi dan Tentang Mebel.

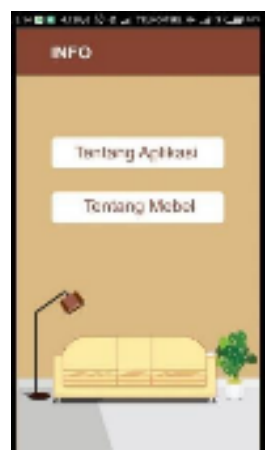

Gambar 4.12 Halaman info 
Perancangan Geographic Information System Berbasis Android Untuk Potensi Mebel Di Kecamatan Tahunan Kabupaten Jepara

5) Tampilan Halaman Tentang Mebel Halaman ini berisi tentang mebel Jepara, kelebihan mebel Jepara dan tips membeli mebel Jepara.

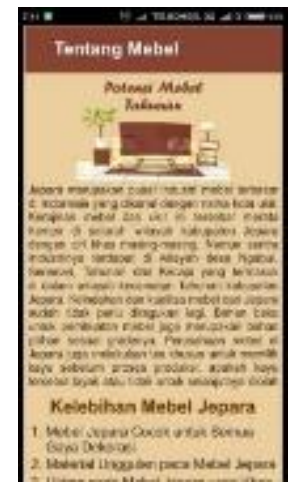

Gambar 4.13 Halaman tentang mebel

6) Tampilan Halaman Daftar Mebel Halaman ini berisi daftar nama dan lokasi usaha mebel yang berada di kecamatan tahunan.

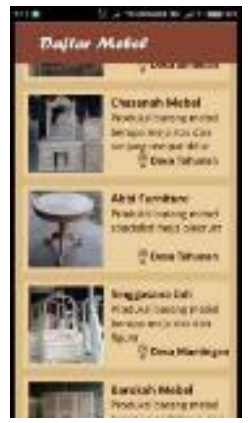

Gambar 4.14 Halaman daftar mebel

7) Tampilan Halaman Detail Info

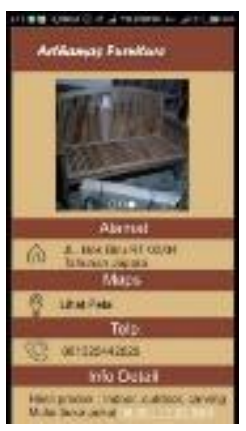

Gambar 4.15 Halaman detail info
8. Tampilan Halaman yang Terintegrasi dengan Google Maps Halaman ini adalah halaman pencarian rute lokasi menggunakan google maps.

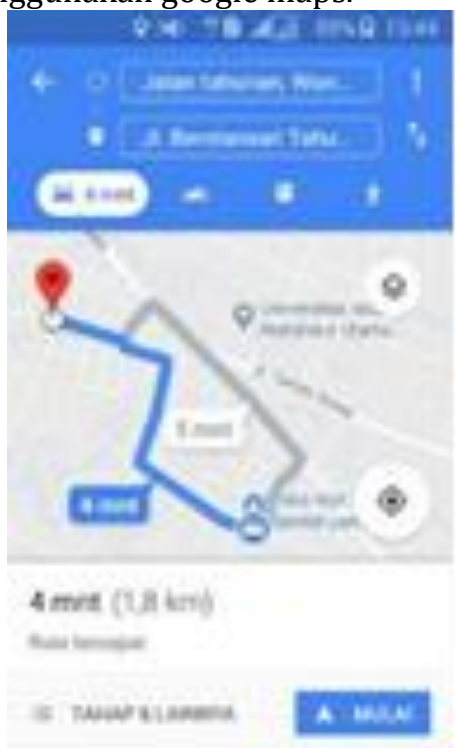

Gambar 4.15 Halaman Google Maps

\subsection{Pengujian Metode}

\subsubsection{Black Box Testing}

Pengujian metode Aplikasi Pometa Jepara memakai metode black box testing yang dilakukan pada seluruh tampilan aplikasi yang disajikan ke dalam table pengujian sesuai fungsi dalam aplikasi.

Tabel 4.1 Hasil Pengujian Black Box Testing

\begin{tabular}{|c|c|c|c|c|}
\hline $\begin{array}{l}\mathbf{N} \\
\mathbf{0}\end{array}$ & $\begin{array}{c}\text { Ske } \\
\text { na } \\
\text { rio } \\
\text { Pen }\end{array}$ & $\begin{array}{c}\text { Hasil Yang } \\
\text { Diharapka } \\
\mathbf{n}\end{array}$ & $\begin{array}{c}\text { Hasil } \\
\text { Penguji } \\
\text { an }\end{array}$ & $\begin{array}{l}\text { Kesi } \\
\text { m } \\
\text { pula } \\
\mathrm{n}\end{array}$ \\
\hline 1 & Icon & $\begin{array}{l}\text { Mun cul } \\
\text { pada } \\
\text { devic e } \\
\text { Andr } \\
\text { oid }\end{array}$ & $\begin{array}{l}\text { Muncul } \\
\text { pada } \\
\text { device } \\
\text { Android }\end{array}$ & Valid \\
\hline 2 & $\begin{array}{l}\text { Spl } \\
\text { as } \\
h \\
\text { scr }\end{array}$ & $\begin{array}{l}\text { Mun cul } \\
\text { saat icon } \\
\text { dikli k }\end{array}$ & $\begin{array}{l}\text { Muncul } \\
\text { saat } \\
\text { icon } \\
\text { diklik }\end{array}$ & Valid \\
\hline
\end{tabular}


Teguh Tamrin ${ }^{1}$, Akhmad Khanif Zyen ${ }^{2}$, Maula Hashina Dina ${ }^{3}$

\begin{tabular}{|l|l|l|l|l|}
\hline 3 & $\begin{array}{l}\text { Halam } \\
\text { an } \\
\text { utama }\end{array}$ & $\begin{array}{l}\text { Men ampi } \\
\text { Ikan tomb } \\
\text { ol info } \\
\text { dan } \\
\text { Dafta r } \\
\text { Meb el }\end{array}$ & $\begin{array}{l}\text { Menam } \\
\text { pilkan } \\
\text { tombol } \\
\text { info dan } \\
\text { Daftar } \\
\text { Mebel }\end{array}$ & Valid \\
\hline 4 & $\begin{array}{l}\text { Fun } \\
\text { gsi } \\
\text { to } \\
\text { mb } \\
\text { ol } \\
\text { Inf }\end{array}$ & $\begin{array}{l}\text { Men } \\
\text { ampi } \\
\text { Ikan } \\
\text { menu } \\
\text { Tent } \\
\text { ang Apli } \\
\text { kasi } \\
\text { dan Tent } \\
\text { ang }\end{array}$ & $\begin{array}{l}\text { Menam } \\
\text { pilkan } \\
\text { menu } \\
\text { Tentan } \\
\text { Aplikasi dan } \\
\text { Tentang } \\
\text { Mebel }\end{array}$ & Valid \\
\\
\hline 5
\end{tabular}

\section{5. kesimpulan}

Berdasarkan hasil pembahasan sebelumnya, maka dapat disimpulkan dari hasil analisis, perancangan, dan pengujian sistem Aplikasi Pometa Jepara adalah :

1. Aplikasi Pometa Jepara ini mempermudah pencarian informasi tentang potensi mebel berada di wilayah kecamatan Tahunan kabupaten Jepara menggunakan perangkat berbasis android dengan sistem operasi minimal kitkat.

2. Aplikasi Pometa Jepara Menampilkan informasi mengenai mebel jepara, profil usaha, dan contoh produk yang dihasilkan.

3. Pada halaman detail informasi mebel, aplikasi ini terintegrasi google maps sehingga memudahkan pengguna mengetahui rute menuju ke lokasi. oleh satu ahli media, dan satu ahli materi serta dengan menyebar 30 angket responden dengan hasil sebagai berikut:

\begin{tabular}{|l|l|c|l|}
\hline No & Benguji & Nilai & Kriteria \\
\hline 1. & Ahli & 95,2 & Sangat \\
& Materi & $\%$ & Layak \\
\hline 2. & Ahli & $100 \%$ & Sangat \\
& Media & Layak \\
\hline 3. & $\begin{array}{l}\text { Responden } \\
\text { Masyarakat } \\
\text { Umum }\end{array}$ & $89 \%$ & $\begin{array}{l}\text { Sangat } \\
\text { Layak }\end{array}$ \\
\hline
\end{tabular}

Berdasarkan tabel hasil pengujian yang dilakukan oleh satu ahli materi, satu ahli media, dan 30 responden, dapat disimpulkan bahwa aplikasi Pometa Jepara ini sangat layak untuk digunakan.

4. Kelayakan aplikasi dilakukan 
Perancangan Geographic Information System Berbasis Android Untuk Potensi Mebel Di Kecamatan Tahunan Kabupaten Jepara

\section{REFERENCES}

S. Lestari, Perkembangan dan Strategi Pengembangan Pembiayaan Usaha Mikro Kecil dan Menengah (UMKM), Jakarta: Deputi Bidang Pengkajian Sumber Daya UMKM, 2006.

D.P. d. P. k. Jepara, Data Potensi Industri Kabupaten Jepara, Jepara: Disperindag, 2017.

K. M. Wibowo, I. Kanedi and J. Jumadi, "Sistem Informasi Geografis (SIG) Menentukan lokasi pertambangan Batu Bara di Provinsi Bengkulu Berbasis Website," Jurnal Media Infotama Universitan Dehasen Bengkulu, vol. XI, no. 1858, pp. 51-52, 2015.

Armanto,"Aplikasi Persebaran Objek Wisata di Kota Depok Berbasis Mobile GIS Memanfaatkan Smartphone Android," Komunikasi, Media dan Informatika, vol. VI, no. 1, pp. 1-8, 2017.

U. N. Sari and dkk, "Aplikasi Sistem Informasi Geografis Identifikasi Persebaran Potensi Daerah Berbasis WEB (Studi Kasus : Kab. Jepara)," Jurnal Geodesi Undip, vol. III, no. 4, pp. 2337-8450, 2014.

M. Saefudin, "Aplikasi Informasi Pariwisata Tempat, Budaya, Kerajinan dan Kuliner Daerah Cirebon Berbasis Android," Simetris, vol. VIII, no. 1, pp. 2252- 4983, 2017.

S. Nazruddin, ANDROID Pemrograman Aplikasi Mobile Smartphone dan Tablet PC Berbasis Android, Bandung: Informatika, 2014.

S. H. S, Mudah Membuat Aplikasi Android, Yogyakarta: Andi, 2011.

M. R. Romi, M. M. Rengkung and V. H. Makarau, "Pengaruh Perkembangan Industri Mebel Terhadap Pola Pemanfaatan Lahan di Desa Leilem Kecamatan Sonder," Universitas Sam Ratulangi, pp. 2-3, 2014.

A. Ratnasari, "Peranan Industri Kecil Menengah (IKM) Dalam Penyerapan Tenaga Kerja di Kabupaten Ponorogo," Jurnal Pendidikan Ekonomi JUPE UNESA, vo;. I, no.3, pp.5-6, 2013.

A. Apriyanto and I. S. Lasodi, "Pembuatan Game Labirin Menggunakan Aplikasi Construct 2 Berbasis Online," Jurnal Elektronik Sistem Informasi dan Komputer JESIK STMIK Bina Mulia, vol. II, no. 2777-888, pp.66-67, 2016.

B. Raharjo, Belajar Pemrograman Web, Bandung: Modula, 2011.

M. S. Mustaqbal, R. F. Firdaus and H. Rahmadi, "Pengujian Aplikasi Menggunakan Black Box Testing Boundary Value Analysis," Jurnal Ilmiah Teknologi Informasi Terapan Universitas Widyatama, vol. I, no. 3, pp. 32-33,2015.

M. Komarudin, "Pengujian Perangkat Lunak Metode Black Box Berbasis Equivalence Partitions pada Aplikasi Sistem Informasi Sekolah," Jurnal Mikrotik UM Metro, vol. VI, pp.1-3, 2016.

P. P. Widodo and Herlawati, Menggunakan UML, Bandung: Informatika, 2011. 
N. Martono, Metodologi Penelitian Kualitatif, Jakarta: Rajawali Pos, 2011.

D. Satori and A. Komariyah, Metodologi Penelitian Kualitatif, Bandung: Alfabeta, 2014.

L. Whitten, D. L. Bentley and C.K. Dittman, Metode Desain dan Analisis Sistem, Yogyakarta: Andi and McGraw-Hill Education, 2004.[19] Sugiyono, Metode Penelitian Administrasi, Bandung: Alfabeta, 2011. 